\title{
Respiratory tract inflammation during the induction of chronic bronchitis in rats: role of C-fibres
}

\author{
N.C. Long, J. Abraham, L. Kobzik, E.A. Weller, G.G. Krishna Murthy, S.A. Shore
}

Respiratory tract inflammation during the induction of chronic bronchitis in rats: role of $C$ fibres. N.C. Long, J. Abraham, L. Kobzik, E.A. Weller, G.G. Krishna Murthy, S.A. Shore. (C) ERS Journals Ltd 1999.

ABSTRACT: The hypothesis that chronic stimulation of $\mathrm{C}$-fibres by inhaled irritants contributes to the inflammatory changes that occur during the development of chronic bronchitis was tested.

The effect of neonatal capsaicin pretreatment on the development of respiratory tract inflammation was examined in a rat model of chronic bronchitis induced by $\mathrm{SO}_{2}$ exposure. Adult capsaicin- and vehicle-treated rats were exposed to $\mathrm{SO}_{2}(250$ parts per million (ppm) $5 \mathrm{~h} \cdot \mathrm{day}^{-1}$ ) for one day, 2 weeks or 4 weeks. Nasal (NL), airway (AL) and bronchoalveolar (BAL) lavages were performed and the number and types of cells in the lavage fluids measured. $\mathrm{SO}_{2}$-induced changes in ventilation were also measured on day 1 of $\mathrm{SO}_{2}$ exposure and in the 3rd and 5th week of exposure.

In the vehicle-treated rats, neutrophils became elevated in NL after just one day of $\mathrm{SO}_{2}$ exposure, in AL after 2 weeks, and in the BAL after 4 weeks. In comparison to vehicle animals, more neutrophils were recovered in the AL of capsaicin-treated rats after one day of $\mathrm{SO}_{2}(p=0.012)$, and in the $\mathrm{BAL}$ after 2 or 4 weeks $(p=0.004$ and $\mathrm{p}=0.01$, respectively). On day $1, \mathrm{SO}_{2}$ caused a transient increase in tidal volume and a sustained decrease in frequency that was not different in capsaicin- and vehicletreated rats. With continued exposure, these ventilatory responses to $\mathrm{SO}_{2}$ were attenuated in both groups of rats.

These data support the hypothesis that the presence of $\mathrm{C}$-fibres limits or delays the inflammation that occurs during the development of chronic bronchitis induced by $\mathrm{SO}_{2}$ exposure. The protective effect of $\mathrm{C}$-fibres is not the result of ventilatory responses to stimulation of these afferents.

Eur Respir J 1999; 14: 46-56.
Physiology Program, Harvard School of Public Health, Boston, MA, USA.

Correspondence: S.A. Shore

Physiology Program

Harvard School of Public Health

665 Huntington Ave.

Boston

MA 02115

USA

Fax: 16174323468

Keywords: Capsaicin

inflammation

pattern of breathing

substance P

sulphur dioxide

tachykinins

Received: November 51997

Accepted after revision December 31998

This study was supported by HL 19170 and ES00002.
Prolonged exposure of humans to respiratory irritants such as cigarette smoke can lead to the development of chronic bronchitis, a syndrome characterized by cough and mucous hypersecretion. Chronic bronchitis is also characterized by airway inflammation [1]. Models of chronic bronchitis, involving long-term exposure to high concentrations of $\mathrm{SO}_{2}$ gas, have been developed in rats and dogs [2-8]. In these models, animals develop many of the histological changes associated with human chronic bronchitis: epithelial damage, mucous hypersecretion, and influx of inflammatory cells into the airway tissue and lumen. In rats, airway obstruction and increased airway responsiveness to inhaled aerosolized methacholine are also observed [8].

Inhaled irritants such as $\mathrm{SO}_{2}$, cigarette smoke, acrolein, and formaldehyde, stimulate $\mathrm{C}$-fibres, a class of unmyelinated sensory nerve fibres, which contain a variety of neuropeptides, including the tachykinins substance P (SP) and neurokinin A (NKA), as well as calcitonin generelated peptide (CGRP) and nitric oxide. Stimulation of Cfibres causes responses that resemble many aspects of chronic bronchitis, including cough [9], mucous secretion [10] and airway narrowing [11]. Stimulation of these nerves also causes an inflammatory response known as neurogenic inflammation, which involves increased airway blood flow [12], increased capillary permeability [13], and increased adherence of neutrophils to the airway vascular endothelium, the first step in the migration of these cells into the airways and lungs [14].

Based on the ability of agents known to induce chronic bronchitis to stimulate C-fibres, as well as the observed responses to $\mathrm{C}$-fibre stimulation, it was hypothesized that these nerve fibres play a role in the pathogenesis of chronic bronchitis. To test this hypothesis, bronchitis was induced by chronic $\mathrm{SO}_{2}$ exposure in normal rats and in rats treated with capsaicin neonatally. Neonatal treatment of rats with capsaicin destroys $\mathrm{C}$-fibres and causes irreversible depletion of tachykinins in the tissues that receive $\mathrm{C}$-fibre innervation [15].

In order to examine the role of C-fibres in the inflammation that occurs during the induction of bronchitis, capsaicin- and vehicle-treated rats were exposed either to air or $\mathrm{SO}_{2}$ for $5 \mathrm{~h} \cdot$ day $^{-1}$ for 1 day, 2 weeks or 4 weeks. Lavages (nasal, airway, and bronchoalveolar) were then performed and the numbers and types of cells in the lavage fluids measured to determine the magnitude and nature of the inflammatory changes due to $\mathrm{SO}_{2}$ exposure. The results show that inflammation, as indicated by the presence of 
lavage neutrophils, is greater, and progresses more rapidly down the respiratory tract in capsaicin- than in vehicletreated rats. These results suggest that rather than contributing to the pathogenesis of chronic bronchitis, C-fibres actually protect the airways during induction of chronic bronchitis by $\mathrm{SO}_{2}$ exposure.

High concentrations of $\mathrm{SO}_{2}$ have been demonstrated to stimulate $\mathrm{C}$-fibres, and stimulation of $\mathrm{C}$-fibres results in rapid shallow breathing [16]. Such a breathing pattern could be expected to limit $\mathrm{SO}_{2}$ penetration to the deep lung. Consequently, animals treated with neonatal capsaicin and lacking such $\mathrm{C}$-fibre-mediated ventilatory reflexes might actually have had greater $\mathrm{SO}_{2}$ exposure in the deep lung and concomitant increased injury and inflammation resulting in greater physiological changes. To examine this hypothesis, minute ventilation and its components, tidal volume and breathing frequency were measured, during air or $\mathrm{SO}_{2}$ exposure in capsaicin and vehicle-treated rats. Because the development of bronchitis results in increased amounts of airway mucus, which may limit the penetration of $\mathrm{SO}_{2}$ to nerve endings, ventilatory responses to $\mathrm{SO}_{2}$ were examined on the first day of exposure and during the $3 \mathrm{rd}$ and 5 th week of $\mathrm{SO}_{2}$ exposure.

\section{Methods}

\section{Animals}

The methods used in this study were approved by the Harvard Medical Area Standing Committee on Animals. Pregnant female Sprague-Dawley rats were purchased from Charles River (Wilmington, MA, USA) and housed individually. The litters from these rats were treated with either capsaicin or vehicle 2 or 3 days after birth. The capsaicin-treated litters were injected subcutaneously with a mixture of $50 \mathrm{mg} \cdot \mathrm{kg}^{-1}$ capsaicin (Spectrum Chemical Mfg. Co., Gardena, CA, USA) dissolved in 10\% ethanol, $10 \%$ Tween- 80 and $80 \%$ saline. After the injection, the rat pups were placed in an open box into which $100 \%$ oxygen was flowing for $30 \mathrm{~min}$ before being returned to their mothers in their original cages. The vehicle-treated rats were injected with a mixture of $10 \%$ Tween- 80 and $10 \%$ ethanol in saline, but otherwise treated identically. At the time the experiments were performed, the rats ranged in age from $3.5-8$ months. Only the female rats were used in this study to minimize problems of interpretation consequent to animal growth over the 4-5 week period during which measurements were obtained. The mean body weight of the capsaicin and vehicle rats on the day that the lavages were performed was $259 \pm 13 \mathrm{~g}$ and $279 \pm 11 \mathrm{~g}$ (mean \pm SEM), respectively.

\section{Assessment of tachykinin depletion by capsaicin}

To confirm the efficacy of the capsaicin pretreatment, the trachea and lungs of one cohort of capsaicin and vehicle rats not exposed to $\mathrm{SO}_{2}$ were assayed for $\mathrm{SP}$ and NKA. Rats were killed with an overdose of sodium pentobarbital. The trachea and lungs of each rat were immediately removed, frozen in liquid nitrogen and stored at $-70^{\circ} \mathrm{C}$ until tachykinins were extracted and assayed by solid phase enzyme-linked immunosorbent assay (ELISA), as previously described $[17,18]$. The antibodies for both SP and NKA were purchased from Peninsula Labs (Belmont, CA, USA). The lower limit of detection of the SP and NKA assays were $3 \mathrm{fmol}$ and 1 fmol respectively. The NKA antibody had a $<3 \%$ cross-reactivity with SP, and Student's t-tests were used to compare levels of SP and NKA in the lungs and trachea of capsaicin and vehicle rats.

\section{$\mathrm{SO}_{2}$ exposure}

Rats were placed in individual wire mesh cells in a $76 \times 46 \times 46 \mathrm{~cm}$ exposure chamber. The $\mathrm{SO}_{2}$ concentration in the air of the chamber was 250 parts per million (ppm), and was monitored continuously by a pulsed fluorescent $\mathrm{SO}_{2}$ analyser (Thermo Electron Series 43; Franklin, MA, USA). The condition of the rats and the $\mathrm{SO}_{2}$ levels in the chamber were checked hourly throughout the exposure period. Capsaicin and vehicle rats were exposed to $\mathrm{SO}_{2}$ at the same time and in the same chamber. The airexposed controls were exposed in an identical chamber to filtered room air. When the animals were not being exposed to $\mathrm{SO}_{2}$ or air, they were housed in group cages (46 rats.cage ${ }^{-1}$ ) under a laminar flow hood.

\section{Protocol}

Rats were exposed either to air or $250 \mathrm{ppm} \mathrm{SO}_{2}$ for $5 \mathrm{~h} \cdot \mathrm{day}^{-1}$ for 1 day, 2 weeks or 4 weeks ( 5 days $\cdot \mathrm{week}^{-1}$ ). The concentration and duration of $\mathrm{SO}_{2}$ exposure were chosen based on previous reports which indicate that this exposure protocol is sufficient to result in a syndrome similar to human chronic bronchitis over a period of 4-5 weeks $[4,5,8,19,20]$. Separate cohorts of rats were used for each of the exposure periods. The rats were lavaged either later the same day or on the day after exposure to air or $\mathrm{SO}_{2}$. For measurements of ventilatory response, the animals were exposed to the same concentrations of $\mathrm{SO}_{2}$ gas for 5 weeks.

\section{Lavages}

To assess the effect of $\mathrm{SO}_{2}$ exposure on airway inflammation, and to assess its distribution along the airway tree, nasal (NL), airway (AL), and bronchoalveolar (BAL) lavages were performed on capsaicin and vehicle rats exposed to air or $\mathrm{SO}_{2}$ for each of the three exposure periods. The AL, which consists of the first few millilitres of lavage fluid collected from the lungs, is considered to be a sample of cells from the central airways. RENNARD et al. [21] demonstrated that the first lavage, which they termed the bronchial lavage, contained a greater concentration of columnar epithelial cells than the subsequent lavages, suggesting that the first lavage samples the airways to a greater extent than the distal lung. A greater proportion of epithelial cells was observed in the present study in the $\mathrm{AL}$ than in the BAL of $\mathrm{SO}_{2}$-exposed rats. In the $\mathrm{AL}$ of $\mathrm{SO}_{2}$ exposed rats, epithelial cells ranged $22-56 \%$ of total cells depending on the animal treatment and the week of exposure. In BAL, epithelial cells were never $>2.8 \%$ of 
total cells. Both AL and BAL were performed because a study of patients with chronic bronchitis by THOMPSON et al. [22] showed a more pronounced increase in the number of neutrophils in bronchial lavage samples, in comparison to distal lavage samples.

Just before the lavages were performed, the rats were killed by injection of a lethal dose of sodium pentobarbital and a tracheostomy was created. To perform the AL, $1 \mathrm{~mL}$ of sterile saline was instilled into the trachea by a syringe, and immediately aspirated. To perform the BAL, $5 \mathrm{~mL}$ of fluid were instilled and then aspirated while the chest was massaged. This was repeated 10 times to make a final volume of $55 \mathrm{~mL}$ of BAL fluid. Finally, to perform the NL, the trachea was clamped off with a haemostat, then $3 \mathrm{~mL}$ of sterile saline were instilled into one nostril, while the liquid was simultaneously withdrawn from the other nostril.

The lavage fluids were centrifuged at $400 \times g$ at $4{ }^{\circ} \mathrm{C}$ for $10 \mathrm{~min}$. The pelleted cells were resuspended in saline, and the number and type of cells were determined as follows. A well-mixed sample from each lavage return was cytocentrifuged onto microscope slides (Cytospin 2; Shandon Southern Instruments, Sewickley, PA, USA), air dried, and stained with Wright-Giemsa stain (VWB Stat Stain, Brisbane, CA, USA). From these slides, a differential count of 600 cells was performed. The number and size of cells found in a separate aliquot $(100 \mu \mathrm{L}$ for NL and AL, and $50 \mu \mathrm{L}$ for BAL) was analysed by a cell counter (Elzone - Particle Data, Elmhurst, IL, USA). The number of cells $>6 \mu \mathrm{m}$ in diameter, along with the differential counts were used to calculate the total number of neutrophils, epithelial cells and macrophages in the lavage fluids.

\section{Statistical analysis of lavage data}

In this study, animals that were pretreated with either capsaicin or vehicle were exposed to either air or $\mathrm{SO}_{2}$. It was of interest to determine whether capsaicin pretreatment altered the response to $\mathrm{SO}_{2}$, as characterized by changes in NL, AL, and BAL numbers of neutrophils and AL numbers of epithelial cells. The analysis was focused on these four primary outcomes, based on previously reported data in a canine model of $\mathrm{SO}_{2}$-induced bronchitis [7] that indicated marked increases in neutrophils and epithelial cells with $\mathrm{SO}_{2}$ exposure. Increased numbers of neutrophils are also the predominant cellular change observed in airway and lung lavage fluid from human chronic bronchitic patients $[22,23]$. To determine if capsaicin pretreatment alone caused any changes in these parameters, lavage fluid was also analysed from air exposed animals.

Because the present data set included animals that were not expected to have significant changes in their lavage parameters (i.e. the air-exposed capsaicin and vehicle rats), an analysis was devised to evaluate the results without the findings being diluted by the presence of these values, as would have occurred with a two-way analysis of variance (ANOVA). Specifically, an ANOVA was performed to assess, in the primary outcomes, 1) whether $\mathrm{SO}_{2}$ exposure caused inflammatory changes in the lavage fluids of capsaicin and vehicle rats, 2) whether there were baseline differences in these inflammatory parameters in capsaicin and vehicle rats exposed to air, and 3) whether there was a difference between the response of capsaicin and vehicle rats to $\mathrm{SO}_{2}$ exposure. A multivariate analysis of variance (MANOVA) model was also suitable to evaluate these three objectives across all of the primary outcomes. In order to control for differences in the total number of cells recovered in the AL and BAL, which may have occurred by the trapping of cells in the mucus, neutrophils were also measured and compared as a fraction of total cells. To normalize the distribution of the data, the base $10 \log$ of the number or percentage of cells was used for all of the statistical analyses described above. Data reported in the figures and tables are the mean \pm SEM of the base $10 \mathrm{log}$ of the number of cells. Multiple comparisons were not corrected for.

In addition to the primary outcomes listed above, epithelial cell numbers were also measured in the NL and BAL, and macrophage numbers in all of the lavage fluids. However, the numbers of these cells were not included in the MANOVA, since, based on previous studies [7, 22, 24], the numbers of these cells were not expected to change. These data are included because the relatively unchanging values show that the lavages were performed in a consistent manner. The p-values for these outcomes in the same comparisons as described above are reported.

\section{Body weight}

The body weights of the rats were measured before and after the four-week exposure period. The body weight data were analysed by ANOVA, and are reported as mean \pm SEM.

\section{Monitoring ventilation}

In order to determine whether differences in the ventilatory response to $\mathrm{SO}_{2}$ between capsaicin and vehicle rats might have contributed to differences in the inflammatory response, ventilation was measured during $\mathrm{SO}_{2}$ exposure. For these experiments, the animals were exposed chronically to $\mathrm{SO}_{2}$ gas $\left(250 \mathrm{ppm}, 5 \mathrm{~h} \cdot\right.$ day $^{-1}, 5$ days $\cdot$ week $^{-1}$ for 5 weeks). Ventilation was monitored on the first day of exposure and once during the $3 \mathrm{rd}$ and the 5 th week. When ventilation was not being monitored, the animals were placed in small wire mesh cages as described above. For measurements of ventilation, rats were placed in a plexiglass restraining tube that served as a nose-only exposure flow plethysmograph. The tube was fitted with a silicone rubber gasket designed to fit snugly around the animal's neck and seal the head from the rest of the body. Once the animal was in the tube, a large piston was moved into placed behind the animal. The piston served to prevent the animal from moving and to seal the body chamber from the outside air. Air displaced at the body surface as the animal breathed, passed across a pneumotachograph $(8 \mathrm{~mm}$ diameter fitted with a screen filter) attached to a differential pressure transducer (Model 163PCO1D75; Omega Engineering Inc., CT, Stamford, USA). The resulting flow signal was analysed by a computer program (BUXCO, Troy, NY, USA) which computed minute ventilation $\left(V^{\prime} \mathrm{E}\right)$, tidal volume $(V \mathrm{~T})$, respiratory frequency $(f \mathrm{R})$, inspiratory $(t \mathrm{I})$, and expiratory $(t \mathrm{E})$ time on a breath-by-breath basis and reported the average of each of these values every minute. The cranial end of the tube was inserted into the 


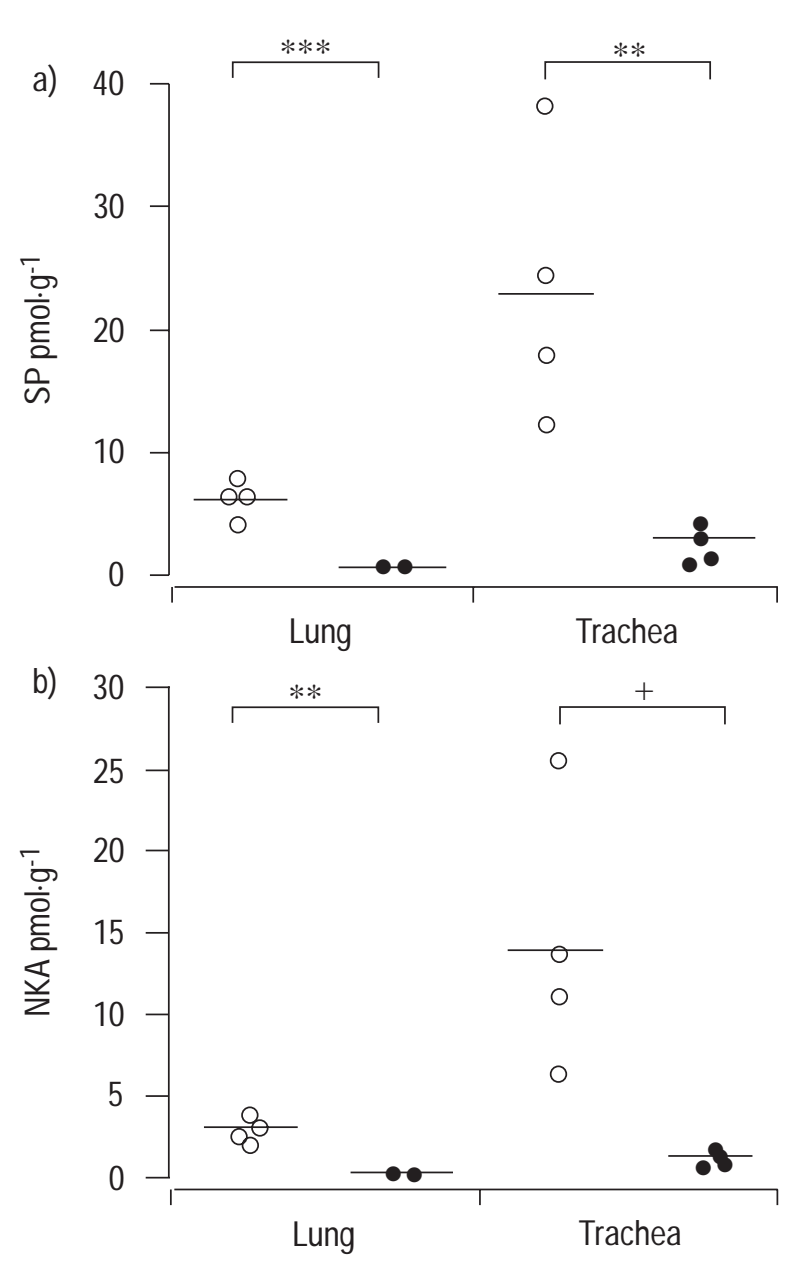

Fig. 1. - Concentration of substance P (SP; a) and neurokin A (NKA; b) in the lung and trachea of capsaicin- $(\bigcirc)$ and vehicle- $(O)$ treated rats, as analysed by enzyme-linked immunosorbent assays. Each point represents data from one rat. $* *: \mathrm{p}<0.01 ;{ }^{* * *}: \mathrm{p}<0.001 ;^{+}: \mathrm{p}<0.02$, differences between vehicle and capsaicin for each tissue. exposure chamber, and after a 45-min adaptation period, the animals were exposed either to filtered air or to $\mathrm{SO}_{2}$ $(250 \mathrm{ppm}$ for $5 \mathrm{~h})$. For each ventilatory parameter, mean values over the $20 \mathrm{~min}$ immediately prior to $\mathrm{SO}_{2}$ exposure were determined for each animal, and data are reported as percentage changes from those values. In each animal, 5 min averages around the time point $10 \mathrm{~min}$ after initiation of $\mathrm{SO}_{2}$, and at every 20 min thereafter were computed. The effect of $\mathrm{SO}_{2}$ exposure or capsaicin treatment on these parameters was then assessed by repeated measures ANOVA.

\section{Results}

\section{Assessment of tachykinin depletion by capsaicin}

The concentration of SP and NKA extracted from the lungs and tracheas were significantly lower in capsaicin than vehicle rats (fig. 1), confirming the efficacy of the treatment.

\section{Effect of $\mathrm{SO}_{2}$ exposures}

Tables 1-3 show the number of neutrophils, epithelial cells, and macrophages in the NL, AL and BAL of vehicle and capsaicin rats exposed to air or $\mathrm{SO}_{2}$ for 1 day, 2 weeks, or 4 weeks. MANOVAs using neutrophil numbers in the NL, AL and BAL and epithelial cell numbers in the $\mathrm{AL}$ as outcome indicators, resulted in an overall significance of $\mathrm{SO}_{2}$ exposure at each time point $(1$ day $\mathrm{p}=$ $0.0005 ; 2$ weeks $\mathrm{p}=0.0001$; 4 weeks $\mathrm{p}=0.0001$ ). ANOVAs were used to assess the time course of $\mathrm{SO}_{2}$-induced changes in each of the parameters ("SO $\mathrm{S}_{2}$ effect" in tables $1-3)$. The results of this analysis are discussed separately below for the vehicle and capsaicin rats.

Table 1. - The number of cells in the nasal lavage fluid of capsaicin- and vehicle-treated rats

\begin{tabular}{|c|c|c|c|c|c|c|c|c|}
\hline & \multicolumn{2}{|c|}{ Air } & \multicolumn{2}{|c|}{$\mathrm{SO}_{2}$} & \multicolumn{4}{|c|}{ p-values } \\
\hline & \multirow{2}{*}{ Vehicle } & \multirow{2}{*}{ Capsaicin } & \multirow{2}{*}{ Vehicle } & \multirow{2}{*}{ Capsaicin } & \multicolumn{2}{|c|}{$\mathrm{SO}_{2}$ effect } & \multicolumn{2}{|c|}{ Capsaicin effect } \\
\hline & & & & & Vehicle & Capsaicin & Air & $\mathrm{SO}_{2}$ \\
\hline \multicolumn{9}{|l|}{1 Day } \\
\hline $\mathrm{n}$ & 7 & 7 & 13 & 12 & & & & \\
\hline Neutrophils & $4.46 \pm 0.36$ & $4.68 \pm 0.31$ & $6.02 \pm 0.10$ & $6.27 \pm 0.12$ & 0.0001 & 0.0001 & 0.54 & 0.32 \\
\hline Epithelial & $5.38 \pm 20$ & $4.68 \pm 0.31$ & $5.46 \pm 0.15$ & $5.41 \pm 0.02$ & 0.80 & 0.95 & 0.99 & 0.84 \\
\hline Macrophages & $4.31 \pm 0.23$ & $3.69 \pm 0.27$ & $5.10 \pm 0.15$ & $5.18 \pm 0.14$ & 0.007 & 0.0001 & 0.06 & 0.75 \\
\hline \multicolumn{9}{|l|}{2 weeks } \\
\hline $\mathrm{n}$ & 5 & 6 & 11 & 11 & & & & \\
\hline Neutrophils & $5.22 \pm 0.14$ & $5.44 \pm 0.19$ & $6.31 \pm 0.13$ & $6.99 \pm 0.15$ & 0.0001 & 0.0001 & 0.43 & 0.0009 \\
\hline Epithelial & $6.13 \pm 0.14$ & $5.86 \pm 0.06$ & $5.92 \pm 0.12$ & $6.10 \pm 0.12$ & 0.27 & 0.19 & 0.21 & 0.23 \\
\hline Macrophages & $5.60 \pm 0.30$ & $5.07 \pm 0.34$ & $5.20 \pm 0.15$ & $5.45 \pm 0.26$ & 0.30 & 0.30 & 0.23 & 0.42 \\
\hline \multicolumn{9}{|l|}{4 weeks } \\
\hline $\mathrm{n}$ & 5 & 4 & 11 & 7 & & & & \\
\hline Neutrophils & $4.35 \pm 0.36$ & $4.31 \pm 0.37$ & $6.51 \pm 0.11$ & $6.84 \pm 0.21$ & 0.0001 & 0.0001 & 0.35 & 0.25 \\
\hline Epithelial & $5.42 \pm 0.33$ & $5.87 \pm 0.19$ & $5.32 \pm 0.09$ & $5.71 \pm 0.15$ & 0.69 & 0.56 & 0.14 & 0.08 \\
\hline Macrophages & $4.45 \pm 0.38$ & $4.72 \pm 0.28$ & $4.93 \pm 0.14$ & $5.29 \pm 0.19$ & 0.13 & 0.12 & 0.48 & 0.20 \\
\hline
\end{tabular}

Data are the $\log$ (base 10) of the number of neutrophils, epithelial cells and macrophages in the lavage fluids of capsaicin- or vehicletreated rats exposed to air or $\mathrm{SO}_{2}$ for 1 day, 2 weeks or 4 weeks. Values given are mean $\pm \mathrm{SEM}$. The fluids were analysed to determine whether $\mathrm{SO}_{2}$ exposure altered the number of cells recovered from vehicle- and capsaicin-treated rats ("SO 2 effect"), and whether capsaicin treatment altered the numbers of cells recovered from air and $\mathrm{SO}_{2}$ exposed rats ("Capsaicin effect"). 
Table 2. - Number of cells in the airway lavage fluid of capsaicin- and vehicle-treated rats

\begin{tabular}{|c|c|c|c|c|c|c|c|c|}
\hline & \multicolumn{2}{|c|}{ Air } & \multicolumn{2}{|c|}{$\mathrm{SO}_{2}$} & \multicolumn{4}{|c|}{$\mathrm{p}$-values } \\
\hline & \multirow{2}{*}{ Vehicle } & \multirow{2}{*}{ Capsaicin } & \multirow{2}{*}{ Vehicle } & \multirow{2}{*}{ Capsaicin } & \multicolumn{2}{|c|}{$\mathrm{SO}_{2}$ effect } & \multicolumn{2}{|c|}{ Capsaicin effect } \\
\hline & & & & & Vehicle & Capsaicin & Air & $\mathrm{SO}_{2}$ \\
\hline \multicolumn{9}{|l|}{1 Day } \\
\hline $\mathrm{n}$ & 7 & 7 & 14 & 14 & & & & \\
\hline Neutrophils & $3.83 \pm 0.25$ & $3.89 \pm 0.25$ & $4.23 \pm 0.20$ & $4.87 \pm 0.14$ & 0.86 & 0.002 & 0.86 & 0.001 \\
\hline Epithelial & $4.25 \pm 0.11$ & $4.53 \pm 0.27$ & $5.08 \pm 0.19$ & $5.30 \pm 0.23$ & 0.02 & 0.03 & 0.47 & 0.33 \\
\hline Macrophages & $5.74 \pm 0.07$ & $5.65 \pm 0.9$ & $5.34 \pm 0.08$ & $5.24 \pm 0.08$ & 0.003 & 0.002 & 0.56 & 0.32 \\
\hline \multicolumn{9}{|l|}{2 weeks } \\
\hline $\mathrm{n}$ & 5 & 6 & 12 & 12 & & & & \\
\hline Neutrophils & $2.94 \pm 0.19$ & $2.91 \pm 0.23$ & $4.92 \pm 0.16$ & $5.03 \pm 0.15$ & 0.0001 & 0.0001 & 0.92 & 0.61 \\
\hline Epithelial & $4.84 \pm 0.06$ & $4.71 \pm 0.16$ & $5.62 \pm 0.14$ & $5.39 \pm 0.14$ & 0.002 & 0.004 & 0.64 & 0.20 \\
\hline Macrophages & $4.96 \pm 0.16$ & $5.19 \pm 0.14$ & $5.39 \pm 0.11$ & $5.25 \pm 0.10$ & 0.03 & 0.74 & 0.28 & 0.35 \\
\hline \multicolumn{9}{|l|}{4 weeks } \\
\hline $\mathrm{n}$ & 6 & 7 & 14 & 10 & & & & \\
\hline Neutrophils & $3.09 \pm 0.24$ & $3.58 \pm 0.29$ & $5.30 \pm 0.13$ & $4.71 \pm 0.11$ & 0.0001 & 0.0003 & 0.12 & 0.17 \\
\hline Epithelial & $4.28 \pm 0.20$ & $4.55 \pm 0.22$ & $5.03 \pm 0.14$ & $4.72 \pm 0.23$ & 0.006 & 0.62 & 0.48 & 0.07 \\
\hline Macrophages & $5.54 \pm 0.07$ & $5.59 \pm 0.12$ & $5.27 \pm 0.21$ & $4.96 \pm 0.19$ & 0.27 & 0.008 & 0.083 & 0.08 \\
\hline
\end{tabular}

Data and statistical analysis as for table 1 .

Vehicle rats. In comparison to air-exposed animals, the number of neutrophils in the NL (table 1) was significantly elevated after exposure to $\mathrm{SO}_{2}$ for just one day and remained elevated at 2 and 4 weeks of $\mathrm{SO}_{2}$ exposure ( $\mathrm{p} \leq 0.0001$ for each time point). No significant changes were seen in NL epithelial cell counts. A significant increase in NL macrophage counts was seen at 1 day, but not at 2 or 4 weeks. In the AL (table 2), neutrophil numbers were not affected by a single day of $\mathrm{SO}_{2}$ exposure, but were significantly increased after 2 or 4 weeks of $\mathrm{SO}_{2}$ exposure $(\mathrm{p} \leq 0.0001$ at both time points). The number of epithelial cells in the AL fluid of $\mathrm{SO}_{2}$-exposed rats was significantly increased compared to the air-exposed rats at all time points examined ( 1 day, $\mathrm{p}=0.02 ; 2$ weeks, $\mathrm{p}=0.002 ; 4$ weeks, $\mathrm{p}=0.006$ ). The num-ber of macrophages in the AL was decreased after 1 day of $\mathrm{SO}_{2}$, increased after 2 weeks, perhaps as a result of the trapping of these cells in mucus, and unchanged at 4 weeks. Vehicle rats showed sig- nificant changes in BAL levels of neutrophils only at 4 weeks of $\mathrm{SO}_{2}$ exposure $(\mathrm{p}=0.007)$ and did not show any significant changes in epithelial cells or macrophages.

Capsaicin rats. As in the vehicle rats, the NL from animals exposed to $\mathrm{SO}_{2}$ for a single day contained significantly more neutrophils than did NL from air-exposed animals, and NL neutrophils remained elevated at 2 and 4 weeks $(p \leq 0.0001$ for each time point). Likewise, NL macrophages were elevated at day 1, but not at any other timepoint. Unlike the vehicle rats, in the capsaicin rats, a single day of $\mathrm{SO}_{2}$ resulted in a significant increase in neutrophils in the AL $(p=0.0002)$. This increase in AL neutrophil numbers persisted after 2 and 4 weeks of $\mathrm{SO}_{2}$ exposure $(\mathrm{p}=0.0001$ and $\mathrm{p}=0.0003$, respectively). The number of epithelial cells in the AL fluid was also elevated after 1 day and 2 weeks of $\mathrm{SO}_{2}$ exposure $(\mathrm{p}=0.03$ and $\mathrm{p}=0.004$, respectively). Macrophage numbers were lower after 1

Table 3. - The number of cells in the bronchoalveolar lavage fluid of capsaicin- and vehicle treated rats

\begin{tabular}{|c|c|c|c|c|c|c|c|c|}
\hline & \multicolumn{2}{|c|}{ Air } & \multicolumn{2}{|c|}{$\mathrm{SO}_{2}$} & \multicolumn{4}{|c|}{ p-values } \\
\hline & \multirow{2}{*}{ Vehicle } & \multirow{2}{*}{ Capsaicin } & \multirow{2}{*}{ Vehicle } & \multirow{2}{*}{ Capsaicin } & \multicolumn{2}{|c|}{$\mathrm{SO}_{2}$ effect } & \multicolumn{2}{|c|}{ Capsaicin effect } \\
\hline & & & & & Vehicle & Capsaicin & Air & $\mathrm{SO}_{2}$ \\
\hline \multicolumn{9}{|l|}{1 Day } \\
\hline $\mathrm{n}$ & 7 & 7 & 14 & 13 & & & & \\
\hline Neutrophils & $4.38 \pm 0.09$ & $5.12 \pm 0.21$ & $4.80 \pm 0.08$ & $5.02 \pm 0.17$ & 0.07 & 0.66 & 0.009 & 0.23 \\
\hline Epithelial & $4.81 \pm 0.22$ & $5.01 \pm 0.20$ & $4.96 \pm 0.15$ & $5.14 \pm 0.19$ & 0.63 & 0.67 & 0.58 & 0.45 \\
\hline Macrophages & $7.1 \pm 0.08$ & $7.17 \pm 0.32$ & $7.19 \pm 0.08$ & $7.08 \pm 0.06$ & 0.43 & 0.45 & 0.63 & 0.22 \\
\hline \multicolumn{9}{|l|}{2 weeks } \\
\hline $\mathrm{n}$ & 5 & 6 & 12 & 12 & & & & \\
\hline Neutrophils & $4.42 \pm 0.09$ & $4.91 \pm 0.23$ & $4.92 \pm 0.12$ & $5.53 \pm 0.17$ & 0.06 & 0.015 & 0.10 & 0.004 \\
\hline Epithelial & $5.30 \pm 0.10$ & $5.77 \pm 0.12$ & $5.18 \pm 0.13$ & $5.38 \pm 0.18$ & 0.63 & 0.11 & 0.12 & 0.31 \\
\hline Macrophages & $7.07 \pm 0.09$ & $7.23 \pm 0.10$ & $7.13 \pm 0.04$ & $7.17 \pm 0.05$ & 0.53 & 0.45 & 0.13 & 0.57 \\
\hline \multicolumn{9}{|l|}{4 weeks } \\
\hline $\mathrm{n}$ & 6 & 7 & 14 & 11 & & & & \\
\hline Neutrophils & $4.55 \pm 0.11$ & $4.61 \pm 0.16$ & $5.29 \pm 0.18$ & $5.87 \pm 0.15$ & 0.007 & 0.0001 & 0.84 & 0.01 \\
\hline Epithelial & $5.30 \pm 0.63$ & $5.24 \pm 0.13$ & $5.37 \pm 0.13$ & $5.23 \pm 0.13$ & 0.72 & 0.97 & 0.78 & 0.40 \\
\hline Macrophages & $6.98 \pm 0.03$ & $7.07 \pm 0.05$ & $6.91 \pm 0.11$ & $7.13 \pm 0.08$ & 0.60 & 0.68 & 0.58 & 0.07 \\
\hline
\end{tabular}

Data and statistical analysis as for table 1 . 


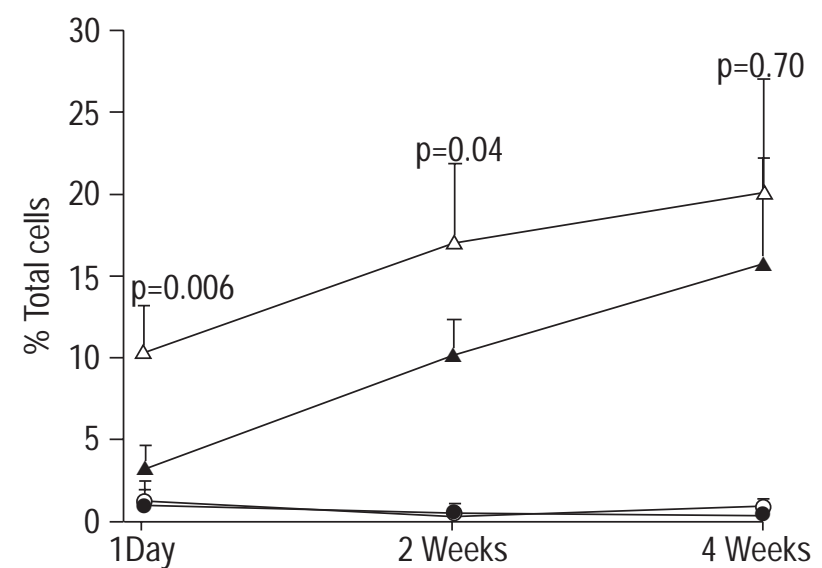

Fig. 2. - Percentage of neutrophils out of total number of cells collected in the airway lavage fluid after exposure to $\mathrm{SO}_{2}$ or air for 1 day, 2 weeks or 4 weeks. The p-values represent differences between the vehicletreated $\mathrm{SO}_{2}$-exposed rats and the capsaicin-treated $\mathrm{SO}_{2}$-exposed rats.

vehicle-air; $\mathrm{O}$ : capsaicin-air; $\boldsymbol{\Delta}$ : vehicle- $\mathrm{SO}_{2} ; \triangle$ : capsaicin- $\mathrm{SO}_{2}$.

day and 2 weeks of $\mathrm{SO}_{2}$ exposure. The number of neutrophils in the BAL fluid of capsaicin rats was significantly increased earlier than in the vehicle rats, i.e. at 2 weeks of $\mathrm{SO}_{2}$ exposure $(\mathrm{p}=0.015)$ (versus 4 weeks in the vehicle rats), and remained elevated at 4 weeks $(p=0.0001)$ of $\mathrm{SO}_{2}$ exposure. No changes in BAL epithelial cell or macrophage counts were seen.

\section{Effect of capsaicin treatment}

Air exposure. The data from rats exposed to air were analysed to determine if there were any baseline differences between the capsaicin and vehicle rats ("capsaicin effect-air" in tables 1-3). The only significant difference between the two groups was in the number of neutrophils recovered from the BAL fluid after one day of air exposure (table 3). Even though statistically significant, this difference was probably not biologically significant, as these neutrophils represented $<1 \%$ of the total number of BAL cells in either group of animals after air exposure. Therefore, it was concluded that there were no important baseline differences between capsaicin and vehicle and that it was not necessary to adjust for baseline differences in the subsequent analyses of $\mathrm{SO}_{2}$-exposed rats.

$\mathrm{SO}_{2}$ exposure. The data from rats exposed to $\mathrm{SO}_{2}$ were analysed to determine if capsaicin and vehicle rats responded differently to this inhaled irritant ("capsaicin effect- $\mathrm{SO}_{2}$ " in tables 1-3). After exposure to $\mathrm{SO}_{2}$, the NL from the capsaicin rats consistently contained more neutrophils than did the NL from vehicle rats (table 1), although this difference was statistically significant only in the rats exposed to $\mathrm{SO}_{2}$ for 2 weeks $(\mathrm{p}=0.0009)$. No differences were seen in the numbers of epithelial cells or macrophages.

Capsaicin rats had significantly more neutrophils in AL than vehicle rats $(\mathrm{p}=0.012)$ after one day of $\mathrm{SO}_{2}$ exposure (table 2). However, this difference was no longer apparent after 2 or 4 weeks of $\mathrm{SO}_{2}$. In order to control for differences in the total number of cells recovered in the $\mathrm{AL}$ which may have occurred by trapping of cells in mucus, neutrophils were also measured and compared as a fraction of total cells (fig. 2). The percentage of neutrophils (analysed as the base $10 \mathrm{log}$ of the per cent cells) in the AL fluid of capsaicin rats exposed to $\mathrm{SO}_{2}$ for 1 day and 2 weeks was significantly higher than that in vehicle rats $(p=0.006$ and $p=0.04$, respectively), but the difference was no longer significant at 4 weeks of exposure. Although both groups of animals had an increased number of epithelial cells in their $\mathrm{AL}$ after $\mathrm{SO}_{2}$ exposure, there was no significant difference in these cell numbers between the capsaicin and vehicle rats at any time point. No significant differences in macrophage numbers were seen.

There was no significant difference in BAL neutrophils between capsaicin and vehicle rats exposed to $\mathrm{SO}_{2}$ for 1 day. However, after 2 or 4 weeks of $\mathrm{SO}_{2}$ exposure, neutrophils were significantly higher in the BAL fluid from capsaicin compared to vehicle rats $(\mathrm{p}=0.004$ at 2 weeks, and $\mathrm{p}=0.01$ at 4 weeks) (table 3 ). When expressed as a percentage of total BAL cells, BAL neutrophils from capsaicin and vehicle were significantly different from each other at 2 weeks $(\mathrm{p}=0.007)$, but not at 4 weeks (fig. 3 ). No differences were seen in the number of epithelial cells or macrophages.

\section{Body weight changes}

The body weight of the rats before exposure to air or $\mathrm{SO}_{2}$, and the change in weight after the 4-week exposure period are shown in table 4. Prior to exposure, there was no significant difference in the body weight of the capsaicin and vehicle rats. Both groups of rats lost weight over the course of the $\mathrm{SO}_{2}$ exposure period, but this weight change was not significantly different from that seen in the air-exposed animals.

\section{Ventilatory responses to $\mathrm{SO}_{2}$}

Table 5 lists baseline ventilatory parameters of capsaicin and vehicle rats measured in the $20-\mathrm{min}$ period

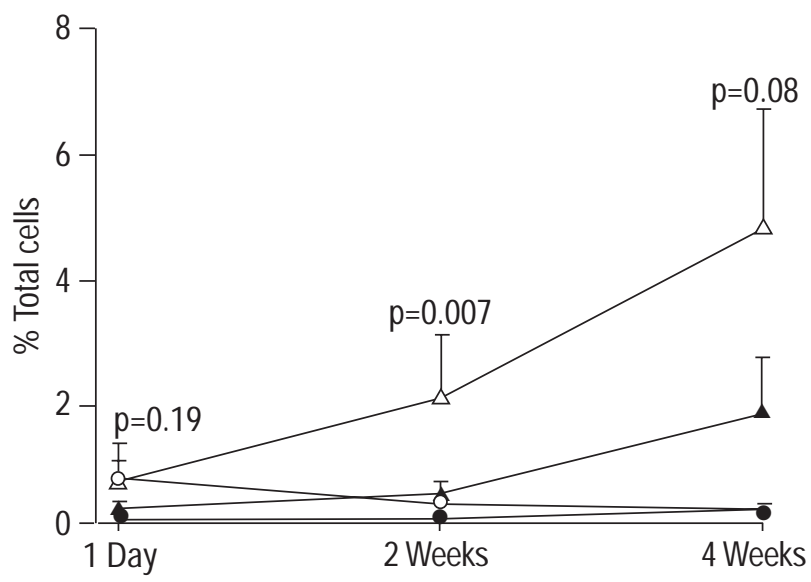

Fig. 3. - Percentage of neutrophils out of total number of cells collected in the bronchoalveolar lavage fluid after exposure to $\mathrm{SO}_{2}$ or air for 1 day, 2 weeks or 4 weeks. The p-values represent differences between the vehicle-treated $\mathrm{SO}_{2}$-exposed rats and the capsaicin-treated $\mathrm{SO}_{2}$-exposed rats. $\bigcirc$ : vehicle-air; $\bigcirc$ : capsaicin-air; $\boldsymbol{\Delta}$ : vehicle- $\mathrm{SO}_{2} ; \triangle$ : capsaicin- 
Table 4. - Change in body weight after 4 weeks of exposure to air or $\mathrm{SO}_{2}$

\begin{tabular}{lccc}
\hline Pretreatment & $\mathrm{n}$ & $\begin{array}{c}\text { Pre-exposure } \\
\text { weight } \mathrm{g}\end{array}$ & $\begin{array}{c}\Delta \text { Body weight } \\
\text { (4 Weeks) } \mathrm{g}\end{array}$ \\
\hline Air & & & \\
Vehicle & 6 & $289 \pm 25$ & $-1 \pm 12$ \\
Capsaicin & 7 & $265 \pm 28$ & $+7 \pm 10$ \\
$\mathrm{SO}_{2}$ & & $274 \pm 11$ & $-9 \pm 5$ \\
Vehicle & 14 & $254 \pm 11$ & $-13 \pm 7$ \\
Capsaicin & 11 & & \\
\hline
\end{tabular}

Values given are mean \pm SEM.

prior to $\mathrm{SO}_{2}$. Capsaicin pretreatment had no significant effect on baseline ventilatory parameters at any time point examined. Baseline $f \mathrm{R}$ was significantly reduced at week $3(\mathrm{p}<0.02)$ and week $5(\mathrm{p}<0.01)$ compared to day 1 in both groups. The decrease in frequency was primarily the result of a significant increase in $t$ E at week $3(\mathrm{p}<0.001)$ and week $5(\mathrm{p}<0.01)$ compared to day 1 . There was no significant effect of week of exposure on the baseline values of any other ventilatory parameter.

Figure 4 shows the effect of the first $\mathrm{SO}_{2}(250 \mathrm{ppm})$ or filtered air exposure on ventilatory parameters. $\mathrm{SO}_{2}$ exposure caused a transient increase in $V_{\mathrm{T}}(\mathrm{p}<0.02)$ and a sustained decrease in $f \mathrm{R}(\mathrm{p}<0.0001)$, but no significant change in $V^{\prime} \mathrm{E}$ compared to air-exposed control rats. There was no significant effect of capsaicin treatment on any of these parameters. The decrease in frequency induced by $\mathrm{SO}_{2}$ exposure was the result of significant increases in both $t \mathrm{I}(\mathrm{p}<0.004)$ and $t \mathrm{E}(\mathrm{p}<0.003)$. The increase in $t \mathrm{I}$ predominated in vehicle rats, whereas the increase in $t \mathrm{E}$ predominated in capsaicin rats.

Figure 5 shows the effect of chronic $\mathrm{SO}_{2}$ exposure on $V^{\prime} \mathrm{E}, V \mathrm{~T}$, and $f \mathrm{R}$. Because no significant effect of drug (vehicle or capsaicin) treatment on these parameters was observed, data from both groups of rats were combined in order to demonstrate the effect of chronic $\mathrm{SO}_{2}$ exposure. There was a significant effect of exposure time on $\mathrm{SO}_{2}$ induced changes in $f \mathrm{R} \quad(\mathrm{p}<0.0005)$ and $V \mathrm{~T} \quad(\mathrm{p}<0.01)$. Chronic exposure to $\mathrm{SO}_{2}$ for 3 or 5 weeks significantly attenuated both the sustained decrease in $f \mathrm{R}$ and the transient increase in $V \mathrm{~T}$ that was observed during $\mathrm{SO}_{2}$ exposure on the first exposure day. $V^{\prime} \mathrm{E}$ was not significantly affected by $\mathrm{SO}_{2}$ exposure on any exposure day.

\section{Discussion}

These results demonstrate that exposure to $\mathrm{SO}_{2}$ gas causes neutrophil influx and epithelial sloughing into the lavage fluids of rats. The inflammatory response to $\mathrm{SO}_{2}$ progressed deeper into the respiratory tract with increased length of exposure. Despite the fact that $\mathrm{C}$-fibres and their tachykinin neuropeptides have the capacity to cause inflammation, and are purported to be mediators of neurogenic inflammation, no evidence was found in this study that $\mathrm{SO}_{2}$ stimulation of $\mathrm{C}$-fibres is responsible for the inflammatory changes associated with $\mathrm{SO}_{2}$-induced chronic bronchitis. In contrast, it was observed that rats which had been depleted of tachykinins by capsaicin pretreatment actually showed a greater degree of respiratory tract inflammation than did the vehicle rats.

The data collected in this study allowed the tracing of the progression of airway responses to $\mathrm{SO}_{2}$, both anatomically and over time. Elevated neutrophil counts appeared in the NL fluid after one day of exposure, in the AL fluid after 2 weeks, and finally the BAL fluid at 4 weeks. The finding that $\mathrm{SO}_{2}$ had its greatest effects in the nose and large airways is consistent with what would be expected from a highly soluble gas such as $\mathrm{SO}_{2}$ [25], and with studies that have shown that $\mathrm{SO}_{2}$ is removed from inhaled air primarily in the upper respiratory tract [26]. Hence the lower airways and alveoli are likely to have received a much smaller dose of $\mathrm{SO}_{2}$. The progression of the inflammation down the respiratory tract with time may represent continuous airway injury and repair caused by the cumulative effect of these smaller doses.

Exposure to $\mathrm{SO}_{2}$ for 1 day, 2 weeks or 4 weeks caused sloughing of epithelial cells into the $\mathrm{AL}$ (table 2), indicating a toxic effect of the $\mathrm{SO}_{2}$ on the epithelium, as previously described [27]. The present study found that the epithelial cells recovered in the lavage fluids of rats exposed to $\mathrm{SO}_{2}$ for 2 or 4 weeks often lacked cilia, suggesting that the epithelial cells themselves underwent morphological changes over the course of the exposure period. These findings are consistent with work by LAMB and REID [4], who found severe damage to airway epithelium after acute exposure to $400 \mathrm{ppm} \mathrm{SO}_{2}$, followed by some degree of regeneration, characterized by a thicker than normal epithelium, with sparse, stunted cilia after 6 weeks. The investigators proposed that these changes in the epithelial lining made it more resistant to injury. They also speculated that the thickening of the

Table 5. - Baseline ventilatory patterns of capsaicin- and vehicle-treated rats measured immediately prior to $\mathrm{SO}_{2}$ exposure

\begin{tabular}{|c|c|c|c|c|c|}
\hline & $V^{\prime} \mathrm{E} \mathrm{mL} \cdot \mathrm{min}^{-1}$ & $V_{\mathrm{T}} \mathrm{mL}$ & $f \mathrm{R}$ breaks. $\mathrm{min}^{-1}$ & $t \mathrm{I} \mathrm{s}$ & $t \mathrm{E} \mathrm{S}$ \\
\hline \multicolumn{6}{|l|}{ Vehicle } \\
\hline Day 1 & $142 \pm 15$ & $1.20 \pm 0.21$ & $129 \pm 15$ & $0.256 \pm 0.049$ & $0.276 \pm 0.041$ \\
\hline Week 3 & $128 \pm 6$ & $1.35 \pm 0.15$ & $102 \pm 11$ & $0.247 \pm 0.026$ & $0.400 \pm 0.034$ \\
\hline Week 5 & $135 \pm 10$ & $1.39 \pm 0.15$ & $100 \pm 10$ & $0.301 \pm 0.046$ & $0.340 \pm 0.019$ \\
\hline \multicolumn{6}{|c|}{ Capsaicin } \\
\hline Day 1 & $138 \pm 22$ & $1.22 \pm 0.16$ & $116 \pm 9$ & $0.293 \pm 0.043$ & $0.287 \pm 0.025$ \\
\hline Week 3 & $122 \pm 8$ & $1.37 \pm 0.08$ & $93 \pm 8$ & $0.338 \pm 0.051$ & $0.391 \pm 0.033$ \\
\hline Week 5 & $142 \pm 8$ & $1.63 \pm 0.09$ & $89 \pm 6$ & $0.327 \pm 0.031$ & $0.394 \pm 0.033$ \\
\hline
\end{tabular}

Results are mean \pm SEM of data from six vehicle and six capsaicin pretreated rats in the 20 min period immediately prior to $\mathrm{SO}_{2}$ exposure. Rats were studied on the first day of $\mathrm{SO}_{2}$ exposure and in the 3rd and 5th week of exposures. Exposures were to 250 parts per billion $\mathrm{SO}_{2}, 5 \mathrm{~h} \cdot$ day $^{-1}, 5$ day $\cdot \mathrm{wk}^{-1} . V^{\prime} \mathrm{E}$ : minute ventilation; $V \mathrm{~T}$ : tidal volume; $f \mathrm{R}$ : respiratory frequency; $t \mathrm{I}, t \mathrm{E}$ : inspiratory and expiratory times, respectively. 

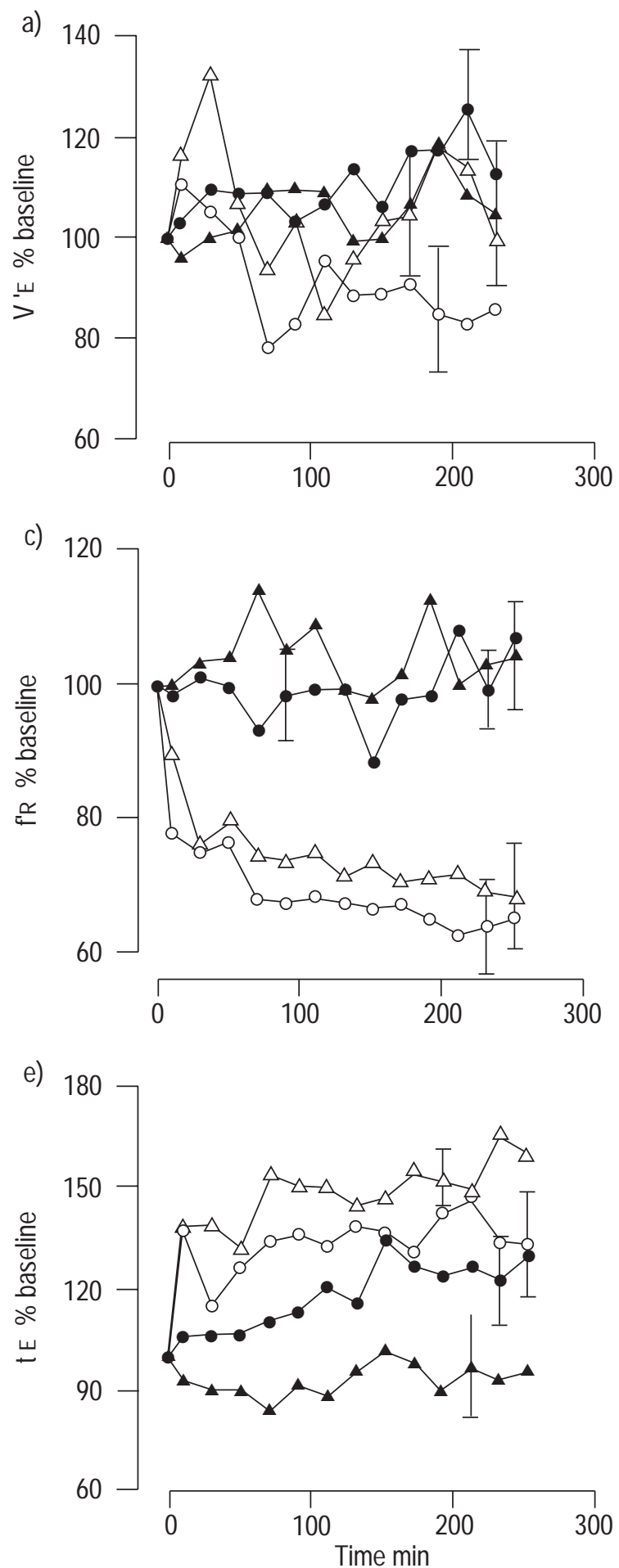

mucus blanket over the course of the exposure period might protect the regenerating epithelial cells. No differences were observed in the number of epithelial cells recovered from lavage fluid of capsaicin or vehicle rats. These observations suggest that the acute toxic effect of $\mathrm{SO}_{2}$ on epithelial cells is not influenced by neurotransmitters released from $\mathrm{C}$-fibres.

To the authors' knowledge, the present study is the first systematic analysis of lavage fluid collected during the
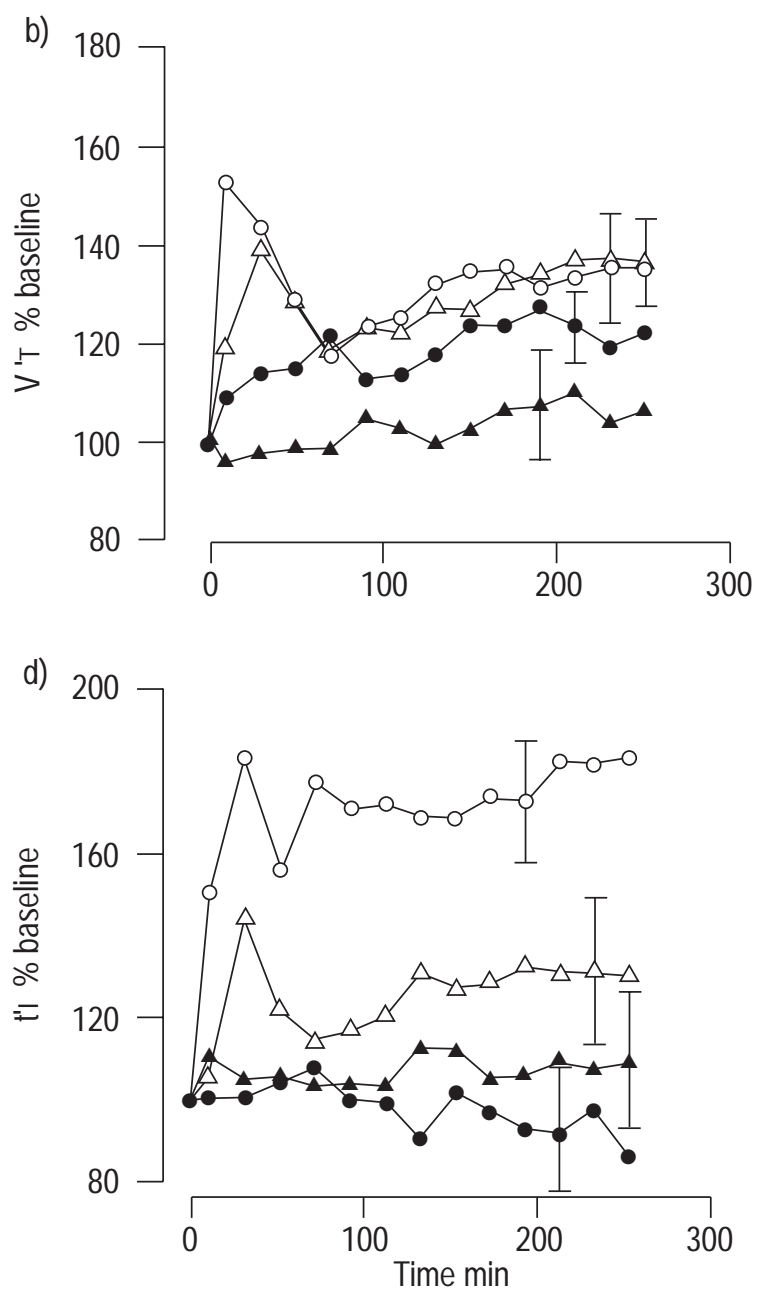

Fig. 4. - Effect of the first $\mathrm{SO}_{2}$ (250 parts per million) (open symbols) or filtered air (closed symbols) exposure on a) minute ventilation $\left.\left(V^{\prime} \mathrm{E}\right), \mathrm{b}\right)$ tidal volume $(V \mathrm{~T}), \mathrm{c})$ respiratory frequency $(f \mathrm{R}), \mathrm{d})$ inspiratory time $(t \mathrm{I})$ and expiratory times $(t \mathrm{E})$. Results are expressed as percentage changes from baseline values (mean values in the 20 -min period prior to $\mathrm{SO}_{2}$ exposure, table 1$)$ and are the mean \pm SEM of data from six vehicle $(\bigcirc)$ and six capsaicin $(\triangle)$ rats exposed to $\mathrm{SO}_{2}$ and nine vehicle $(\bullet)$ and four capsaicin $(\boldsymbol{\Delta})$ rats exposed to air.

course of the development of chronic bronchitis by $\mathrm{SO}_{2}$ exposure in rats. The finding of an increased number of neutrophils, with little change in the number of macrophages or lymphocytes in the lavage fluids matches observations made by SHORE et al. [7], who used the same $\mathrm{SO}_{2}$ model in dogs. An increase in neutrophils is also the most pronounced change observed in the lung and airway lavage fluid of patients with chronic bronchitis [22, 23]. In contrast, tissue sections of airways from patients with 


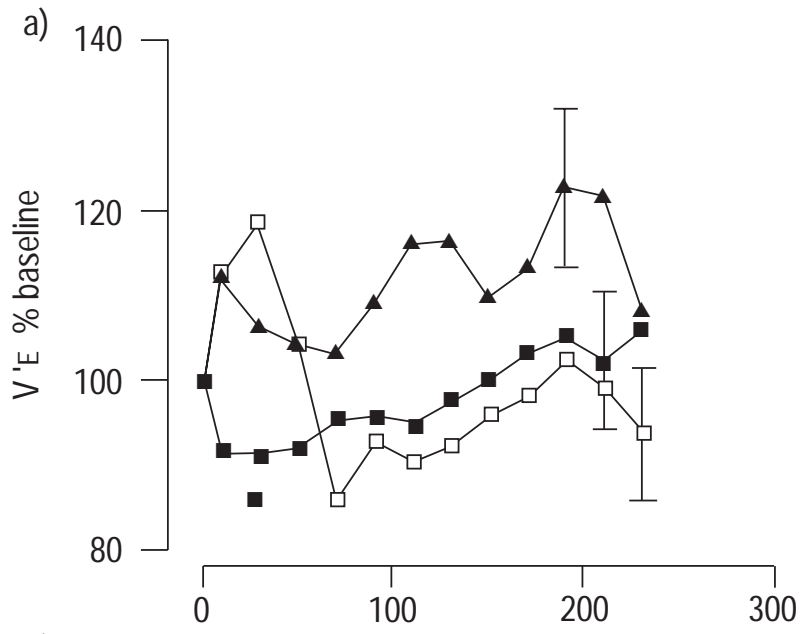

b)
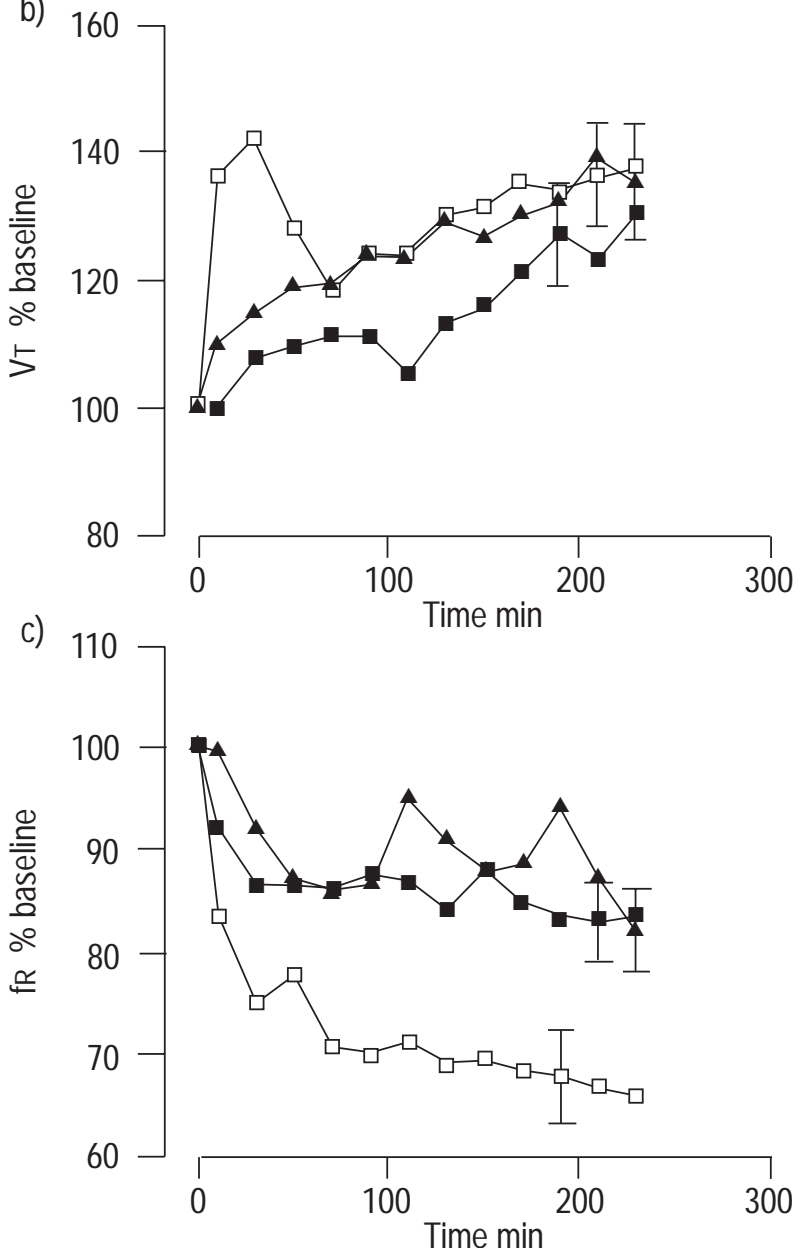

Fig. 5. - Time course of the effect of $\mathrm{SO}_{2}$ exposure on a) minute ventilation $(V \mathrm{E}), \mathrm{b})$ tidal volume $(V \mathrm{~T})$, and c) respiratory frequency $(f \mathrm{R})$. Six vehicle and six capsaicin rats were chronically exposed to $\mathrm{SO}_{2}$ gas ( 250 parts per million, $5 \mathrm{~h} \cdot \mathrm{day}^{-1}, 5 \mathrm{day}^{\cdot} \mathrm{week}^{-1}$ for 5 weeks). Values shown are mean \pm SEM. On the first day of $\mathrm{SO}_{2}$ exposure and once during the $3 \mathrm{rd}$ and 5 th week of exposure, the animals were placed in nose only exposure tubes that served as body plethysmographs during the $\mathrm{SO}_{2}$ exposure. Results are expressed as percentage changes from baseline values (mean values for the 20-min period immediately prior to $\mathrm{SO}_{2}$ exposure; table 5). Because no significant effect of drug (vehicle or capsaicin) treatment on these parameters was observed, data from both groups of rats were combined in order to demonstrate the effect of chronic $\mathrm{SO}_{2}$ exposure. chronic bronchitis demonstrate infiltration by lymphocytes and macrophages [24]. The airway tissue of these rats was not examined, but in dogs exposed to $\mathrm{SO}_{2}$, subepithelial mononuclear cell infiltration is observed [6]. One explanation for the differences in the nature of the inflammatory cells in the airway lumen versus the airway tissue is that there are differences in the nature of the chemotactic factors and adhesion molecules expressed by epithelial versus subepithelial cells.

It was found that inflammation was greater, and progressed more rapidly down the respiratory tract of capsaicin than of vehicle rats. These findings are consistent with an earlier report from the authors' laboratory using the same model of chronic bronchitis [19]. This study showed that while $\mathrm{SO}_{2}$ exposure increases the pulmonary responsiveness of both capsaicin and vehicle rats to inhaled aerosolized methacholine, the change in responsiveness was greater in the capsaicin rats. In addition, capsaicin rats had increased smooth muscle in their airway walls, and increased tracheal contractility, which may contribute to the increase in airway responsiveness. The enhancement of these changes in the structure and function of the airways could result, in part, from the increased inflammatory response that occurs in the capsaicin rats (tables 1-3).

Studies using other models of inflammation have shown similar alterations in the inflammatory response to irritants or infectious agents in capsaicin-treated animals. It was observed that the inflammatory response to the intratracheal instillation of endotoxin was greater in capsaicin than vehicle rats [28]. Other investigators have reported a greater degree of pulmonary or airway inflammation associated with infection with Mycoplasma pulmonis or with inhalation of hydrogen sulphide gas or ozone in capsaicin versus vehicle rats (for a review see [29]).

There are several possible explanations for the higher degree of pulmonary inflammation seen in capsaicin rats after $\mathrm{SO}_{2}$ exposure. Firstly, $\mathrm{SO}_{2}$ stimulates C-fibres [16] which in the lungs evokes a variety of physiological responses that may protect the lung from damage by noxious agents. For example, stimulation of C-fibres increases mucous secretion, ciliary beat frequency, and cough $[10$, 30], which would help to dilute and clear the irritant from the lung. C-fibre stimulation also has central effects such as the induction of a rapid shallow breathing pattern [16], which might tend to limit penetration of the gas into the lungs. However, the present results indicate that ventilatory responses to $\mathrm{SO}_{2}$ stimulation of $\mathrm{C}$-fibres is not an important determinant of the more pronounced inflammatory response and the greater increase in airway responsiveness [6] observed in capsaicin rats. In the vehicle rats, the initial response to $\mathrm{SO}_{2}$ exposure was not rapid shallow breathing, but rather a breathing pattern characterized by slower and deeper breaths (fig. 4), and this response was not different in rats treated neonatally with capsaicin and lacking $\mathrm{C}$-fibres.

A second factor which could contribute to the greater degree of inflammation seen in capsaicin rats is that animals that lack C-fibres may be less able to resolve tissue injury, resulting in elevated or prolonged release of inflammatory mediators, including those that are chemotactic for neutrophils. The concept that capsaicin rats are less able to resolve the airway injury induced by $\mathrm{SO}_{2}$ exposure is supported by studies suggesting that SP is 
involved in wound healing $[31,32]$. SP, NKA, CGRP and nitric oxide, all of which are released by $\mathrm{C}$-fibres, have a number of effects that could contribute to the resolution of tissue injury including synthesis of connective tissue, proliferation of epithelial cells, and increases in blood flow to the airways [12-32, 33].

Even though $\mathrm{SO}_{2}$ has been shown to stimulate C-fibres and stimulation of $\mathrm{C}$-fibres has been shown to result in rapid shallow breathing [16], this rapid shallow breathing was not observed in naive rats exposed for the first time to $\mathrm{SO}_{2}$ (fig. 4). High concentrations of $\mathrm{SO}_{2}$ have also been shown to inhibit slowly adapting stretch receptors (SARs) [34]. It is likely that the latter effect was dominant in altering the pattern of breathing, because the increase in $V \mathrm{~T}$ and prolongation of $t \mathrm{I}$, which were the main consequences of acute $\mathrm{SO}_{2}$ exposure in vehicle rats, are consistent with changes that occur following inhibition of the Hering-Breuer inflation reflex by which SARs normally terminate a breath [34]. Laryngeal receptors with responses similar to SARs are also inhibited by $\mathrm{SO}_{2}[35]$ and may have contributed to the observed effects of $\mathrm{SO}_{2}$ on $V \mathrm{~T}$ and the timing of breathing. The observation that in capsaicin animals, increases in $t \mathrm{E}$ predominated over increases in $t \mathrm{I}$ despite similar changes in $f \mathrm{R}$, suggests that $\mathrm{SO}_{2}$ stimulation of C-fibres does modify the breathing pattern, but such changes are unlikely to have had important effects on the ultimate delivery of $\mathrm{SO}_{2}$ to the respiratory tract.

After 3 or 5 weeks of $\mathrm{SO}_{2}$ exposure, the ventilatory response to $\mathrm{SO}_{2}$ exposure was markedly diminished compared to the first day of exposure (fig. 5). It is possible that the increased presence of mucus in the airways [8] of animals exposed chronically to $\mathrm{SO}_{2}$ diluted the gas to such an extent as to prevent it reaching and inhibiting the activity of SARs. It is also possible that chronic airway injury induced by $\mathrm{SO}_{2}$ exposure caused a more permanent damage to these receptors.

In summary, these data show that exposure to high concentrations of $\mathrm{SO}_{2}$ causes epithelial sloughing and inflammation of the respiratory tract. The inflammatory response progressed along the respiratory tract over the course of the exposure period, and more inflammation appeared earlier in the capsaicin rats. These data support the hypothesis that the presence of C-fibres limits or delays the inflammation that occurs during the development of chronic bronchitis induced by $\mathrm{SO}_{2}$ exposure. The mechanism of this response is not known, but does not appear to involve stimulation of ventilatory reflexes.

Acknowledgments. The authors would like to thank R. Hennessey and the late W.A. Skornik for their excellent technical assistance on this project.

\section{References}

1. Thompson $\mathrm{AB}$, Mueller $\mathrm{MB}$, Heires $\mathrm{AJ}$, et al. Aerosolized beclomethasone in chronic bronchitis: improved pulmonary function and diminished airway inflammation. Am Rev Respir Dis 1992; 146: 389-395.

2. Chakrin LW, Saunders LZ. Experimental chronic bronchitis: pathology in the dog. Lab Invest 1974; 30: 145154.
3. Farone A, Huang S, Paulauskis J, Kobzik L. Airway neutrophilia and chemokine mRNA expression in sulfur dioxide-induced bronchitis. Am J Respir Cell Mol Biol 1995; 12: 345-350.

4. Lamb D, Reid L. Mitotic rates, goblet cell increase and histochemical changes in mucus in rat bronchial epithelium during exposure to sulphur. $J$ Pathol Bacteriol 1968; 96: 97-111.

5. Reid L. An experimental study of hypersecretion of mucus in the bronchial tree. Br J Exper Pathol 1963; 44: 437-445.

6. Seltzer J, Scanlon PD, Drazen JM, Ingram RH, Reid L. Morphologic correlation of physiologic changes caused by $\mathrm{SO}_{2}$-induced bronchitis in dogs. The role of inflammation. Am Rev Respir Dis 1984; 129: 790-797.

7. Shore SA, Kariya ST, Anderson K, et al. Sulfur dioxideinduced bronchitis in dogs: effect of airway responsiveness to inhaled and intravenous methacholine. $A m$ Rev Respir Dis 1987; 135: 840-847.

8. Shore S, Kobzik L, Long NC, et al. Increased airway responsiveness to inhaled methacholine in a rat model of chronic bronchitis. Am J Respir Crit Care Med 1995; 151: 1931-1938.

9. Kohrogi H, Nadel JA, Malfroy B, et al. Recombinant human enkephalinases (neutral endopeptidases) prevents cough induced by tachykinins in awake guinea pigs. $J$ Clin Invest 1989; 84: 781-786.

10. Richardson PS, Webber SE. The control of mucus secretion in the airways by peptidergic mechanisms. Am Rev Respir Dis 1987; 136: S72-S76.

11. Lundberg JM, Martling CR, Saria A. Substance P and capsaicin induced contraction of human bronchi. Acta Physiol Scand 1983; 119: 49-53.

12. Piedimonte G, Hoffman JIE, Husseini WK, Hiser WL, Nadel JA. Effect of neuropeptides released from sensory nerves on blood flow in the rat airway microcirculation. $J$ Appl Physiol 1992; 72: 1563-1570.

13. Lundberg JM, Saria A. Capsaicin-sensitive vagal neurons involved in control of vascular permeability. Acta Physiol Scand 1982; 115: 521-523.

14. Umeno E, Nadel JA, McDonald DM. Neurogenic inflammation of the rat trachea: fate of neutrophils that adhere to venules. J Appl Physiol 1990; 69: 2131-2136.

15. Lundberg JM, Brodin E, Saria A. Effects and distribution of vagal capsaicin-sensitive substance $P$ neurons with special reference to the trachea and lungs. Acta Physiol Scand 1983; 119: 243-252.

16. Coleridge JCG, Coleridge HM. Afferent vagal $\mathrm{C}$ fibre innervation of the lungs and airways and its functional significance. Rev Physiol Biochem Pharmacol 1984; 99: 2-110.

17. Lilly CM, Bai TR, Shore SA, Hall AE, Drazen JM. Neuropeptide content of lungs from asthmatic and nonasthmatic patients. Am J Respir Crit Care Med 1995; 151: 548-553.

18. Martins MA, Shore SA, Gerard NP, Gerard C, Drazen JM. Peptidase modulation of the pulmonary effects of tachykinins in tracheal superfused guinea pig lungs. J Clin Invest 1990; 85: 170-176.

19. Long NC, Martin JG, Pantano R, Shore SA. Airway hyperresponsiveness in a rat model of chronic bronchitis: role of C fibers. Am J Respir Crit Care Med 1997; 155: 1222-1229.

20. Killingsworth CR, Paulauskis JD, Shore SA. Substance P content and preprotachykinin gene 1 mRNA expression in a rat model of chronic bronchitis. Am J Respir Cell Mol Biol 1996; 14: 334-340. 
21. Rennard SI, Ghofouri MO, Thompson AB, et al. Fractional processing of sequential bronchoalveolar lavage to separate bronchial and alveolar samples. Am Rev Respir Dis 1990; 141: 208-217.

22. Thompson AB, Daughton D, Robbins RA, Ghafouri MA, Oehlerkin M, Rennard SI. Intraluminal airway inflammation in chronic bronchitis: characterization and correlation with clinical parameters. Am Rev Respir Dis 1989; 140: 1527-1537.

23. Martin TR, Raghu G, Maunder RJ, Springermeyer SC. The effects of chronic bronchitis and chronic air-flow obstruction on lung cell populations recovered by bronchoalveolar lavage. Am Rev Respir Dis 1985; 132: 254-260.

24. Saetta M, Di Stefano A, Maestrelli P, et al. Activated Tlymphocytes and macrophages in bronchial mucosa of subjects with chronic bronchitis. Am Rev Respir Dis 1993; 147: 301-306.

25. Dalhamn T, Strandberg L. Acute effect of sulphur dioxide on the rate of ciliary beat in the trachea of rabbit, in vivo and in vitro, with studies on the absorptional capacity of the nasal cavity. Int J Air Poll Water Poll 1961; 4: 154-167.

26. Frank NR, Yoder RE, Brain JD, Yokohama E. $\mathrm{SO}_{2}(35 \mathrm{~S}$ labeled) absorption by the nose and mouth under conditions of varying concentration and flow. Arch Environ Health 1969; 18: 315-322.

27. Man SFP, Hulbert WC, Man G, Mok K, Williams DJ. Effects of $\mathrm{SO}_{2}$ exposure on canine pulmonary epithelial functions. Exp Lung Res 1989; 15: 181-198.
28. Long NC, Frevert C, Shore SA. Role of C-fibres in the inflammatory response to intratracheal lipopolysaccharide (LPS). Am J Physiol (Lung Cell Mole Physiol) 1996; 15: L425-L431.

29. Shore SA, Lilly CM, Gaston B, Drazen JM. Neural networks in the lung. In: Holgate ST, ed. Immunopharmacology of the Respiratory System. San Diego, Academic Press, 1995; pp. 123-145.

30. Wong LB, Miller IF, Yeates DB. Pathways of substance P stimulation of canine tracheal ciliary beat frequency. $J$ Appl Physiol 1991; 70: 267-273.

31. Gallar J, Pozo MA, Rebollo I, Belmonte C. Effects of capsaicin on corneal wound healing. Invest Opthamol Vis Sci 1990; 31: 1968-1974.

32. Nilsson J, von Euler AM, Dalsgaard C-J. Stimulation of connective tissue cell growth by substance $\mathrm{P}$ and substance K. Nature 1985; 315: 61-63.

33. White SR, Hershenson MB, Sigrist KS, Zimmermann A, Solway J. Proliferation of guinea pig trachea epithelial cells induced by calcitonin gene-related peptide. $A m J$ Respir Cell Mol Biol 1993; 8: 592-596.

34. Davies A, Dixon M, Callanan D, Huszczuk A, Widdicombe JG, Wise JCM. Lung reflexes in rabbits during pulmonary stretch receptor block by sulphur dioxide. Respir Physiol 1978; 34: 83-101.

35. Mortola JP, Citterio G, Agostoni E. Sulphur dioxide block of laryngeal receptors in rabbits. Respir Physiol 1985; 62: 195-202. 